\title{
Reefing Line Tension in CPAS Main Parachute Clusters
}

\author{
Eric S. Ray ${ }^{1}$ \\ Jacobs Engineering, Houston, TX, 77058
}

\begin{abstract}
Reefing lines are an essential feature to manage inflation loads. During each Engineering Development Unit (EDU) test of the Capsule Parachute Assembly System (CPAS), a chase aircraft is staged to be level with the cluster of Main ringsail parachutes during the initial inflation and reefed stages. This allows for capturing high-quality still photographs of the reefed skirt, suspension line, and canopy geometry. The over-inflation angles are synchronized with measured loads data in order to compute the tension force in the reefing line. The traditional reefing tension equation assumes radial symmetry, but cluster effects cause the reefed skirt of each parachute to elongate to a more elliptical shape. This effect was considered in evaluating multiple parachutes to estimate the semi-major and semi-minor axes. Three flight tests are assessed, including one with a skipped first stage, which had peak reefing line tension over three times higher than the nominal parachute disreef sequence.
\end{abstract}

$=$ Semi-major axis of an ellipse

$=$ Semi-minor axis of an ellipse

$\mathrm{A}, \mathrm{B}, \mathrm{C}, \mathrm{D}, \mathrm{E}=2$-D points on image

$\mathrm{CDT} \quad=$ Cluster Development Test (series)

CPAS $\quad=$ Capsule Parachute Assembly System

$\delta \quad=$ Over-inflation angle, $\delta=\delta_{1}-\delta_{2}$

$\delta_{1} \quad=$ Angle between radial at skirt and parachute centerline

$\delta_{2}=$ Suspension line half convergence angle (from centerline)

$\mathrm{D}_{\mathrm{o}} \quad=$ Nominal parachute diameter based on constructed area, $\mathrm{D}_{\mathrm{o}}=\sqrt{4 \cdot \mathrm{S}_{\mathrm{o}} / \pi}$

$\mathrm{D}_{\mathrm{R}} \quad=$ Reefed diameter of a parachute, $\mathrm{D}_{\mathrm{R}}=\mathrm{L}_{\mathrm{r}} / \pi$

$\mathrm{e}=$ Eccentricity of an ellipse

EDU $\quad=$ Engineering Development Unit

$\mathrm{F}_{\mathrm{k}} \quad=$ Canopy reaction force along radial $\mathrm{k}$

$\mathrm{F}_{\mathrm{R}} \quad=$ Total axial force (load) in reefed parachute

$\mathrm{F}_{\mathrm{SL}} \quad=$ Suspension line tension force

GPS $\quad=$ Global Positioning System

$\mathrm{L}_{\mathrm{r}} \quad=$ Reefing line length

$\mathrm{L}_{\mathrm{s}} \quad=$ Suspension line length

MDT $=$ Main Development Test (series)

MPCV $=$ Multi Purpose Crew Vehicle (Orion)

$\mathrm{N}_{\mathrm{c}} \quad=$ Number of parachutes in a cluster

$\mathrm{N}_{\mathrm{G}} \quad=$ Number of gores in a parachute canopy

$\Omega \quad=$ Tangent angle of reefing line attachment point in skirt plane

PCDTV $=$ Parachute Compartment Drop Test Vehicle (missile-shaped)

$\phi \quad=$ Polar angular position of reefing line attachment point

PTV $\quad=$ Parachute Test Vehicle (truncated Orion boilerplate)

$\mathrm{r}=$ Radius from canopy centerline to reefing line attachment point

RC $=$ Ramp Clear (usually chosen as start of test)

$\mathrm{S} / \mathrm{N} \quad=$ Serial Number

$\mathrm{S}_{\mathrm{o}} \quad=$ Parachute canopy open reference area based on constructed shape

${ }^{1}$ Analysis Engineer, Aeroscience and Flight Dynamics, 2224 Bay Area Blvd, Houston, TX, AIAA Member.

American Institute of Aeronautics and Astronautics 
$\mathrm{T}_{\mathrm{RL}} \quad=$ Tension force in parachute reefing line

UTC $\quad=$ Coordinated Universal Time

YPG $\quad=$ Yuma Proving Ground

\section{Introduction}

DEFING lines are a critical feature to restricting peak loads of the Main parachutes of the Orion Multi Purpose Crew Vehicle (MPCV). The $116 \mathrm{ft} \mathrm{D}_{\mathrm{o}}$ Main parachutes are deployed during the final phase of the Capsule Parachute Assembly System (CPAS) to decelerate Orion to a safe landing speed, as described in Ref. 1. A failure of the reefing system would lead to a skipped stage and possibly excessive loads (as described in a separate paper ${ }^{2}$ ). In order to optimize the reefing line design, it is desired to evaluate the peak reefing line tension experienced during flight tests. As explained in Ref. 3, the theoretical reefing line tension is a function of the riser tension and geometry. The geometric angles can be obtained empirically from photogrammetric analysis.

Previous publications have described CPAS photogrammetric analysis of time-varying video. ${ }^{4}$ The discussion of photogrammetry in this paper will focus on analysis of still imagery, mostly from chase aircraft, and the challenges of synchronizing photographs with time varying onboard load measurements.

\section{Over-Inflation Geometry}

The tension force in the Main reefing line, $\mathrm{T}_{\mathrm{RL}}$, is determined from the following parameters, illustrated in Figure 1:

- $\quad$ Riser tension from load cell, $\mathrm{F}_{\mathrm{R}}$

- Suspension line half convergence angle, $\delta_{2}$

- Over-inflation angle, $\delta$

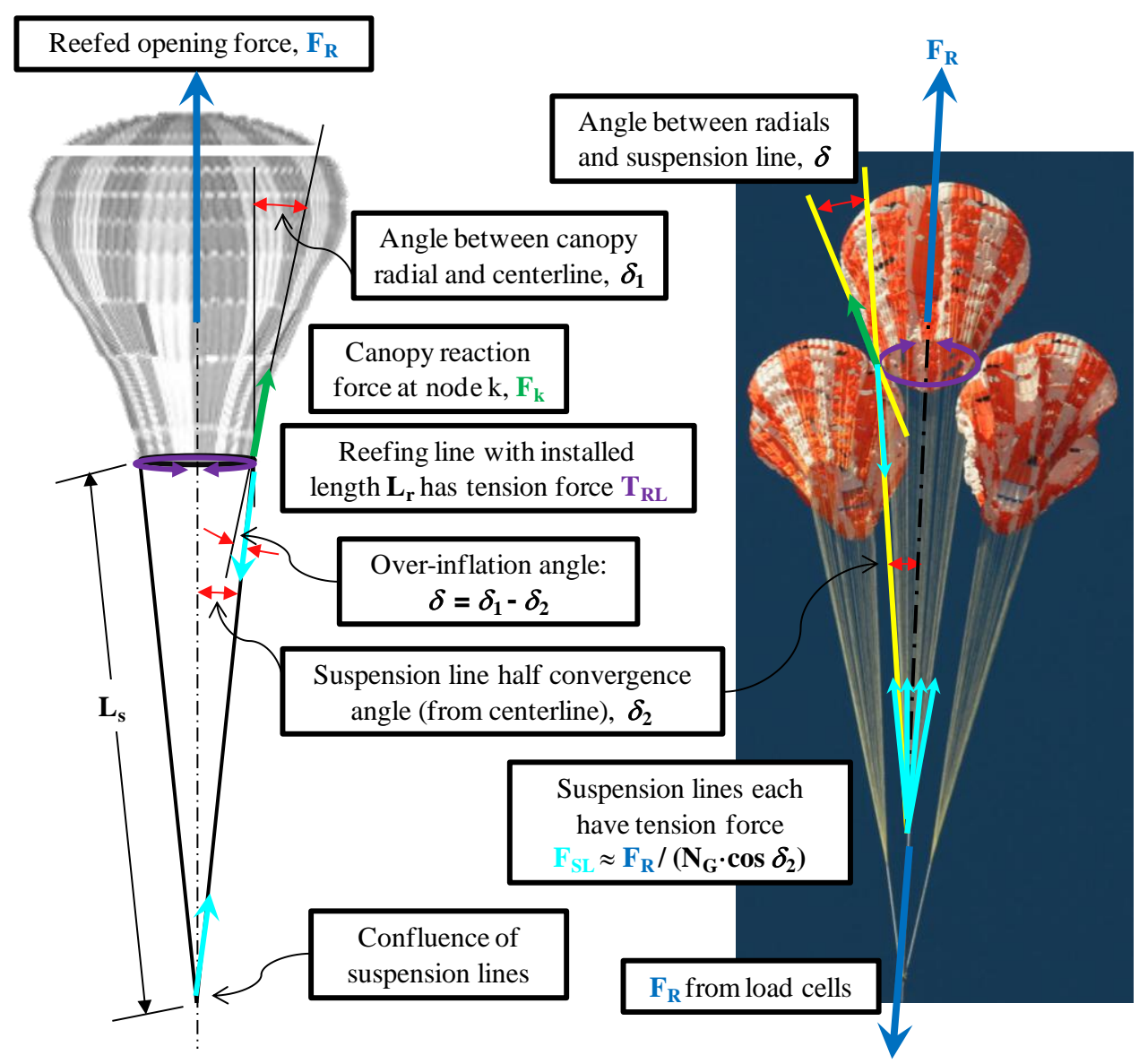

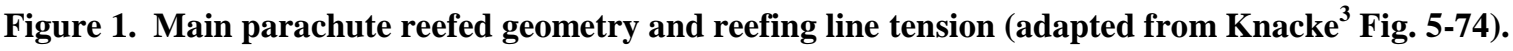


The reefing line tension force is typically derived using assumptions of a static system (neglecting deceleration) and a circular canopy, as in Refs. 5 and 6. Consider the force of a suspension line, $\mathrm{F}_{\mathrm{SL}}$, being transmitted at node $\mathrm{k}$ to its corresponding canopy radial, $\mathrm{F}_{\mathrm{k}}$, as illustrated in Figure 2. The reefing retention system is connected to the skirt via reefing rings. Each ring is attached to the skirt at the interface between a suspension line and radial line. The reefing line tension will provide an inward force towards adjacent nodes. Because the reefing line passes through reefing rings, each node on the skirt may slide along the reefing line until reaching an equilibrium location. Assuming radial symmetry, the angle between nodes is easily computed based on the number of suspension lines (equal to the number of gores, $\mathrm{N}_{\mathrm{G}}$ ). The diameter is the reefing line length, $\mathrm{L}_{\mathrm{r}}$, divided by pi. It follows from geometry that the suspension line half convergence angle for a circular skirt is defined by Eq. 1, where $D_{R}$ is the reefed diameter and $\mathrm{L}_{\mathrm{s}}$ is the suspension line length.

$$
\sin \delta_{2}=\frac{\mathrm{D}_{\mathrm{R}}}{2 \cdot \mathrm{L}_{\mathrm{s}}}
$$

The angle of the radial from the vertical, $\delta_{1}$, is highly dependent on the canopy porosity and is determined empirically from either wind tunnel or flight testing. For convenience, these angles then define the over-inflation angle, $\delta=\delta_{1}-\delta_{2}$. The reefing line force is calculated according to Eq. 2 . As is often noted in the literature, this equation indicates that for a given riser load, the reefing line tension increases with a more bulbous inflated shape or longer suspension lines.

$$
\mathrm{T}_{\mathrm{RL}}=\frac{\mathrm{F}_{\mathrm{R}} \cdot\left(\tan \delta-\tan \delta_{2}\right)}{2 \pi}
$$

CPAS Main Development Test (MDT) flights generally showed that a single Main parachute does have an approximately axisymmetric shape when reefed, whose dimensions may be measured in flight. ${ }^{7}$ However, the multiple Main parachutes flown during every Cluster Development Test (CDT) exhibited considerable flattening when reefed, most likely due to mutual aerodynamic interference. A typical cluster configuration is shown in
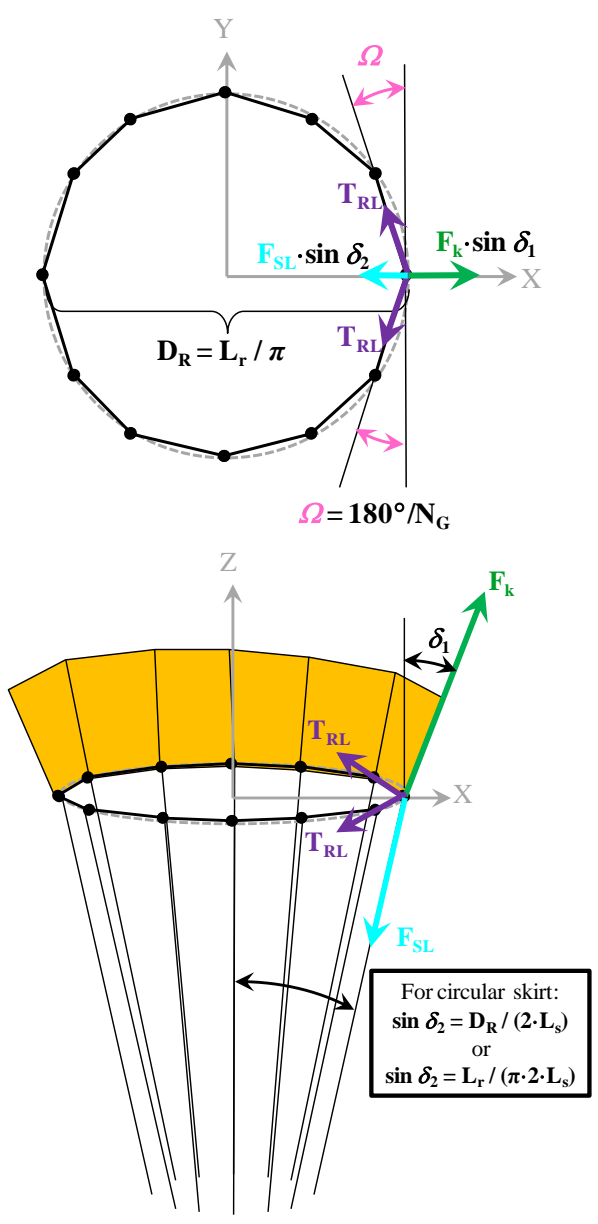

Figure 2. Reefing line force balance for circular skirt.

Figure 3 where the inlet geometry changes over time. These elongated shapes also lead to considerable load asymmetry, as measured by both the $\operatorname{Ares}^{8}$ and $\operatorname{CPAS}^{9}$ flight test programs.
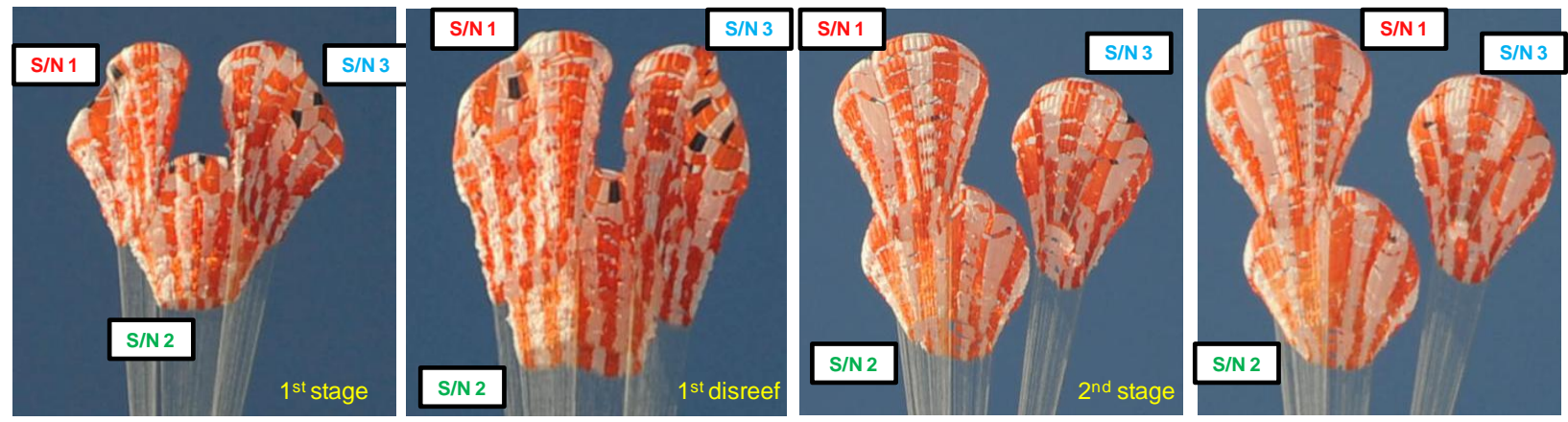

Figure 3. Evolution over time of elliptical skirt inlets from ground views of CDT-3-1.

A more general approach would be to assume an elliptical shape of given eccentricity e, semi-major axis length $a$, and semi-minor axis length $b$. An example skirt plane for a canopy with a small number of gores is illustrated in 
the upper left section of Figure 4. In the example shown, the reefing nodes are distributed approximately evenly. A force balance at radials intersecting the $\mathrm{X}$ and $\mathrm{Y}$ axes can be used to explain the irregular inflated canopy shape. Assuming the reefing tension is constant at each node, the radial angle will tend to be more vertical at semi-minor axis $\left(\phi=90^{\circ}\right)$ than at the semi-major axis $\left(\phi=0^{\circ}\right)$. This would tend to result in the higher over-inflation angles at intersections with the $\mathrm{X}$ axis.
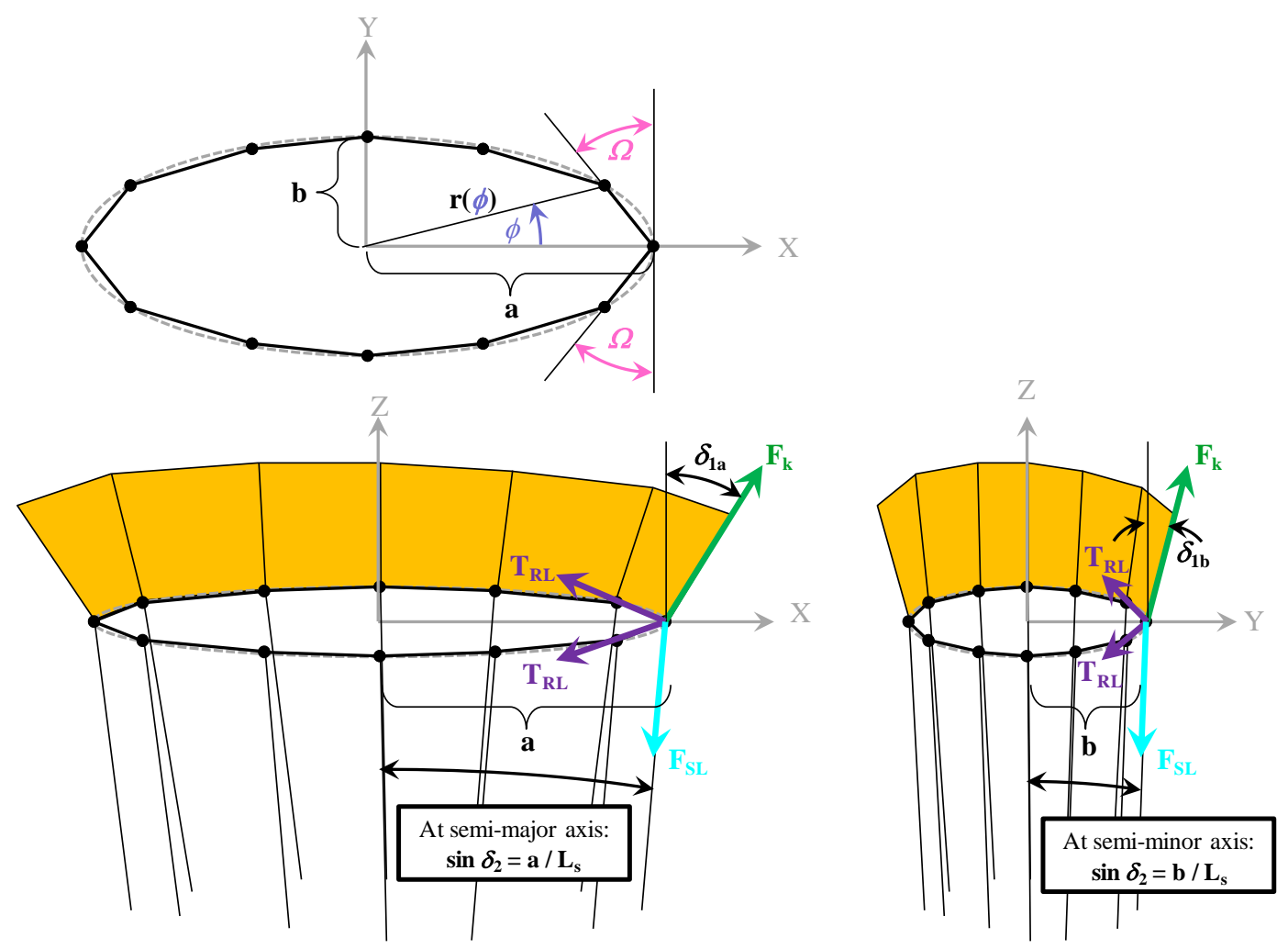

Figure 4. Elliptical geometry of reefed skirt with even spacing illustrating the force balance at planes of symmetry.

Photogrammetric analysis of test imagery can readily be performed to obtain the radial incidence angles at both the semi-major axis, $\delta_{1 \mathrm{a}}$, and at the semi-minor axes, $\delta_{\mathrm{lb}}$, as will be shown. However, determining the reefing line angle in the horizontal plane, $\Omega$, is not straightforward for non-circular shapes. The node locations are not directly observable during flight. While it is possible to use upward-looking High Definition (HD) cameras on the payload to fit an assumed shape (such as an ellipse), the images are not of high enough resolution to resolve the individual node locations. Because every node is free to travel along the skirt (as the reefing ring at each node slides along the reefing line), no particular spacing scheme (e.g. equal $\phi$ or equal arc-segment length) can be assumed. In fact, it is likely that suspension lines will cluster near the semi-major axis and spread out from the semi-minor axis, as illustrated in Figure 5. This clustering is problematic for modeling because the local over-inflation angle is very sensitive to the local value of $\Omega$. Yet the test data generally show a larger over-inflation angle at the semi-minor axes, consistent with Figure 5. 

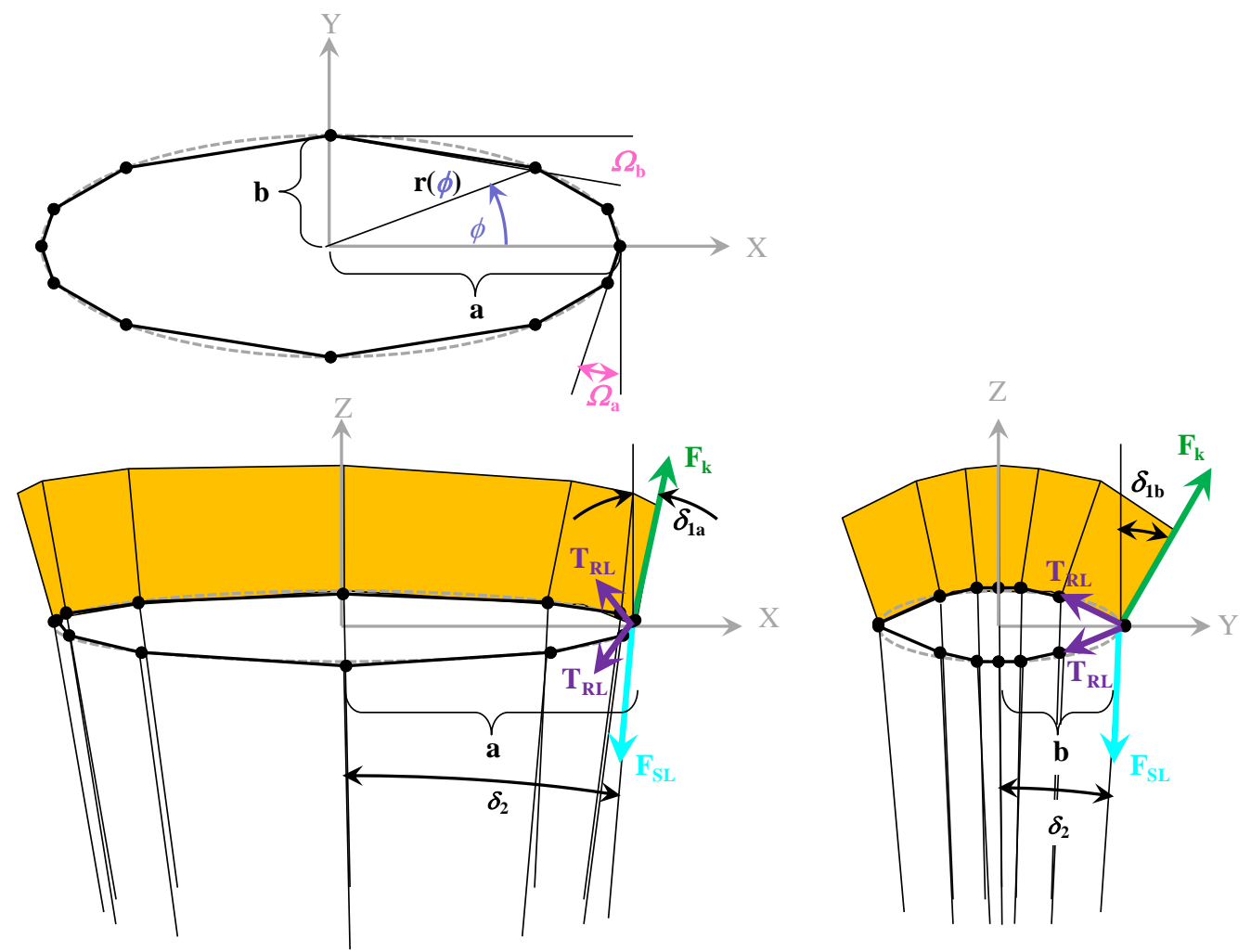

Figure 5. Elliptical geometry of reefed skirt with clustering at the semi-major axis.

In theory, a rudimentary system of equations could be used to determine a best fit solution of the reefing line tension and the distribution of all reaction force vectors $\left(\mathrm{F}_{\mathrm{k}}\right)$. The vertical and horizontal force balances provide two equations at each node. The force in each suspension line could be assumed to be a particular fraction of the measured total riser load. One option is to assume each suspension line carries an equal load. Another option is to fit a curve through asymmetric loads measured previously in flight ${ }^{9}$ to determine a distribution. A final equation can relate each node to the next assuming the tension force is equal. This is essentially a finite-element approach.

However, the system is further complicated in that the reaction forces at each radial do not necessarily lie in a plane parallel to the parachute axis. An assumption would have to be made about the orientation of each reaction force vector (say, each could lie in a plane determined by the centerline and the local radius vector, $r$ ). Current knowledge does not provide a basis for making such an assumption.

Fluid Structure Interaction (FSI) may offer a path forward to fully modeling the system. The Team for Advanced Flow Simulation and Modeling (T*AFSM) at Rice University ${ }^{10}$ has already demonstrated FSI solutions for a reefed Main parachute ${ }^{11}$ and a cluster of fully inflated Main parachutes ${ }^{12}$, though the combination of these features may be particularly challenging.

The interim method employed in this study is to "circularize" the elliptical shape by taking an average of the measured extreme values of over-inflation angles and suspension line angles. Confidence is gained in this approach by comparing the "circularized" average of measured convergence angles with the theoretical circular convergence angle from Eq. 1.

\section{Image Analysis}

\section{A. Photographic Procedure}

Most CPAS flight tests include at least one chase aircraft to make airborne observations of the test as it is conducted. This has evolved into a complex choreography of several chase aircraft being staged at various altitudes to best capture certain events. ${ }^{13}$ Currently a chase helicopter stationed at the Yuma Proving Ground (YPG) is maneuvered to be at the same altitude as the test vehicle at Main parachute deployment in order to obtain profile pictures. Such a picture is shown in Figure 6 from CDT-3-1. The same image is shown twice to illustrate how the over-inflation angle is measured on both the left and right side of Main S/N 3, which presents the semi-major axis. 
Main S/N 2 happened to present the approximate semi-minor axis at that time. The original TIF image was read into the GNU Image Manipulation Program (GIMP) ${ }^{14}$ in order to pick off $\mathrm{X}$ and $\mathrm{Y}$ locations of the points labeled A through $\mathrm{E}$. These points define segments, whose angles $\left(\eta_{\mathrm{BA}}, \eta_{\mathrm{DB}}\right.$, etc.) are computed using the arc tangent function. The difference between the segment angles is the over-inflation angle for that side. Whenever possible, the left and right edges are averaged to reduce error.

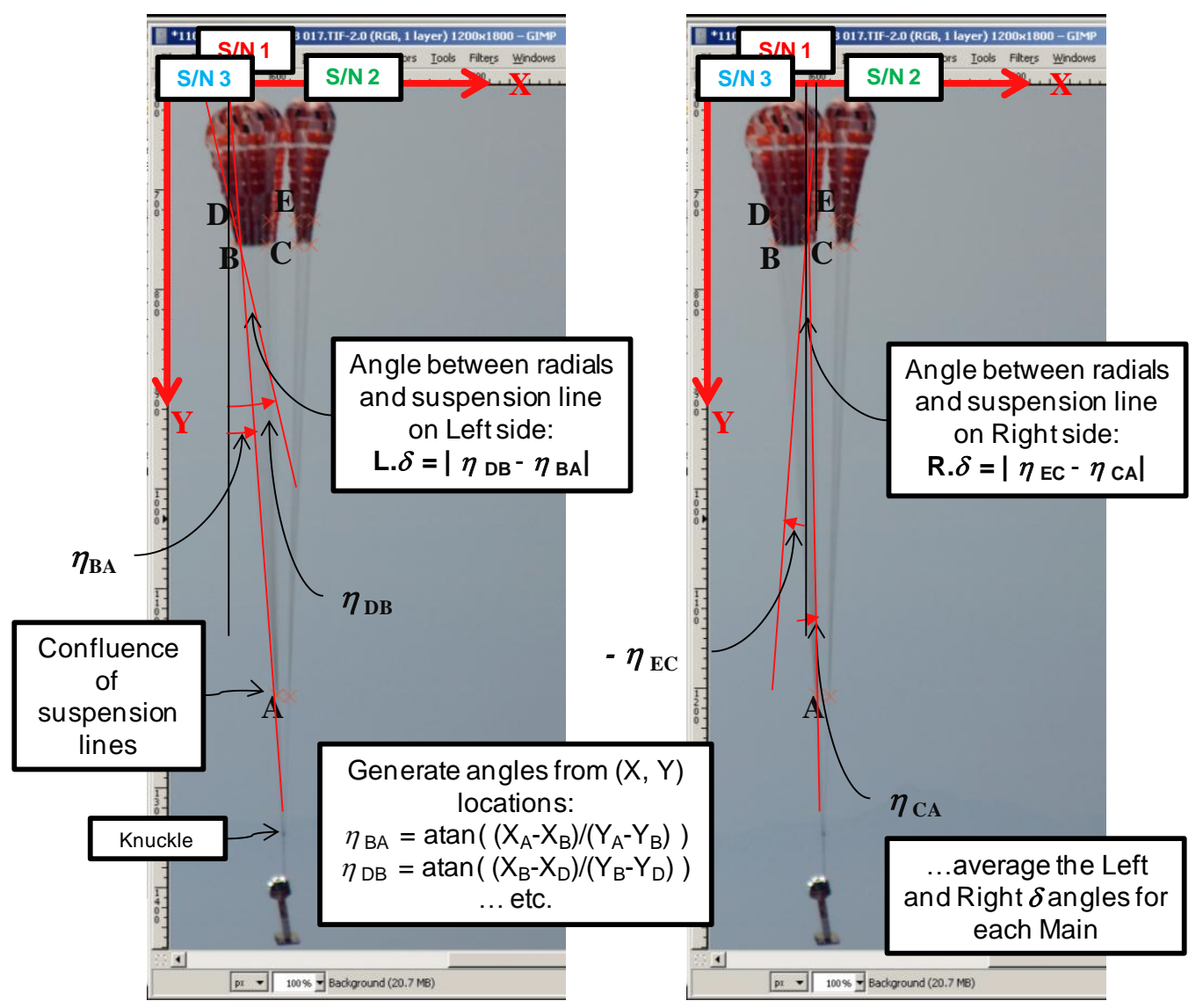

Figure 6. Analysis of the left and right sides of Main S/N 3 during CDT-3-1, resulting in the over-inflation angle of the semi-major axis.

\section{B. Still Camera Synchronization}

The still camera used in CDT-3-1 had a GPS unit attached which embedded GPS readings into the metadata of each photo. The fields included geodetic latitude and longitude, as well as altitude (height above ellipsoid, HAE). ${ }^{15}$ An example of the locations is shown in Figure 7. The chase helicopter (orange) is clearly orbiting the Robby Drop Zone and intercepting the test vehicle (blue) as planned, following it to the ground. 
The fields of most concern to this analysis are the GPS time stamp and the internal camera timestamp, which are needed to synchronize photogrammetric data to loads traces. The inflation events take place on the order of tenths of a second. The GPS timestamp will be highly accurate in absolute time, but unfortunately only updates at approximately $2 \mathrm{~Hz}$. The camera also has an internal clock which is set manually. Although the internal clock is generally not set to an absolute time with any accuracy, it does record a relative timestamp with a precision of hundredths of a second.

The first step in synchronizing the photographs is to use the GPS timestamp to shift the internal clock times to the approximate Coordinated Universal Time (UTC) within about 2 seconds. Next, photographs of key events such as mortar firing and touchdown are compared to the video timeline. An average offset is computed and applied to the relative times. This places the photos to within about 0.2 seconds of their true times. Data are generally shifted in time to be relative to ramp clear (RC).

Some of the photographs are shown in the altitude history of Figure 8. The Best Estimate Trajectory of the Parachute Compartment Drop Test Vehicle (PCDTV) is compared to GPS data from the chase helicopter metadata. As planned, the helicopter is at about the same altitude as the payload during Main parachute deployment, but the helicopter descends more slowly, maintaining a separation of a couple thousand feet during Main steady-state. This allows for photography of the canopies with a unique perspective from above, which is often useful to observe any damage that occurs during deployment. The chase helicopter altitude data have sudden jumps which are not physically possible. This simply indicates that the GPS camera unit has a relatively high position uncertainty, specifically Vertical Dilution of Precision (VDOP), compared to the onboard avionics.

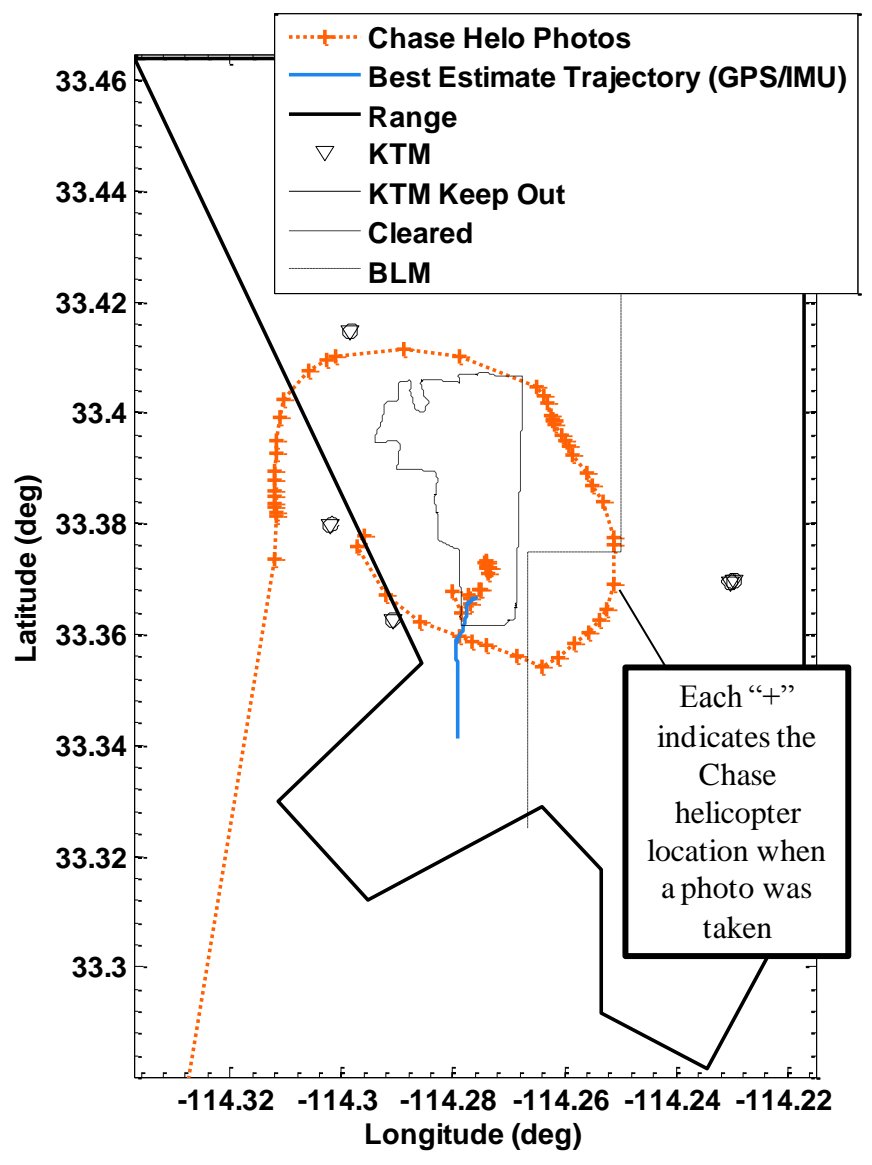

Figure 7. Trajectory of CDT-3-1 chase helicopter from GPS. 


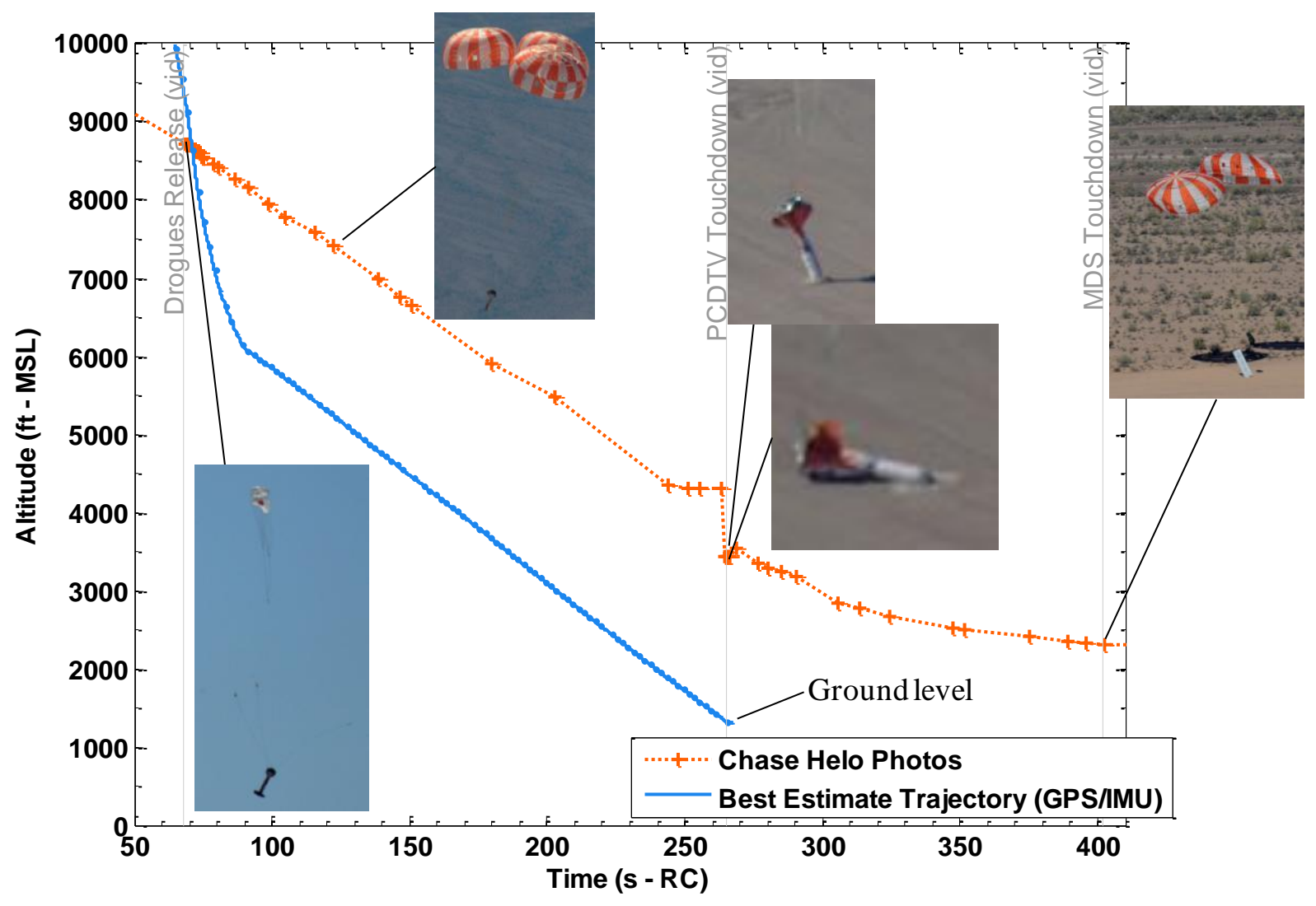

Figure 8. Key photographs are synchronized to timeline events on this altitude history plot.

\section{Selected Test Results}

To date, over-inflation analysis has been conducted on three of the six EDU tests. Each of those assessed involved a cluster of three Main parachutes. CDT-3-1 and CDT-3-6 had a similar cluster reefing schedule, but with significantly more photographs in the latter case. The CDT-3-5 sequence included a planned skipped first stage. The instrumentation used to measure the parachute axial loads is described in Ref. 16.

\section{A. CDT-3-1: First EDU Test}

The synchronized shutter times for the CDT-3-1 Main first and second stage are compared to the measured loads in Figure 9 and Figure 10. Each dashed vertical line indicates when an image was taken and its corresponding filename is displayed. A burst of photographs were taken as the Main parachute deployed and immediately after the first stage peak load. The photo taken about 79 seconds after ramp clear was just after Main S/N 3 visibly disreefed. Two of the photos from second stage were taken within a second after the peak load and another two were taken near the end of the stage. Over-inflation angles were measured for seven representative instants, each circled in the figures. The images were saved in multiple formats. The GPS metadata was extracted from a ".jpg" version of each image, but the image analysis was performed on the corresponding ".TIF" version to avoid compression artifacts. 


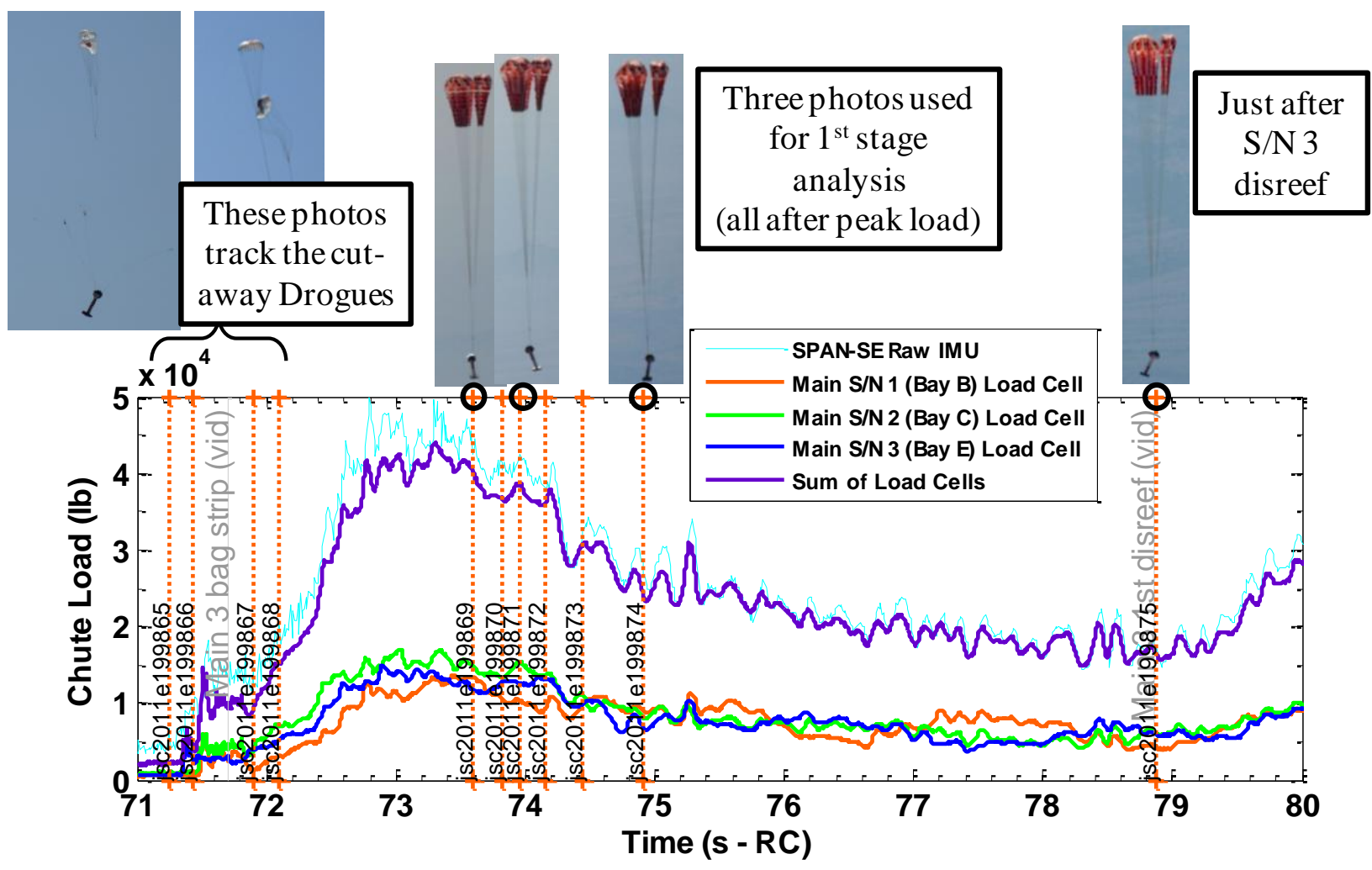

Figure 9. Photographs synchronized to Main $1^{\text {st }}$ stage parachute loads during CDT-3-1.

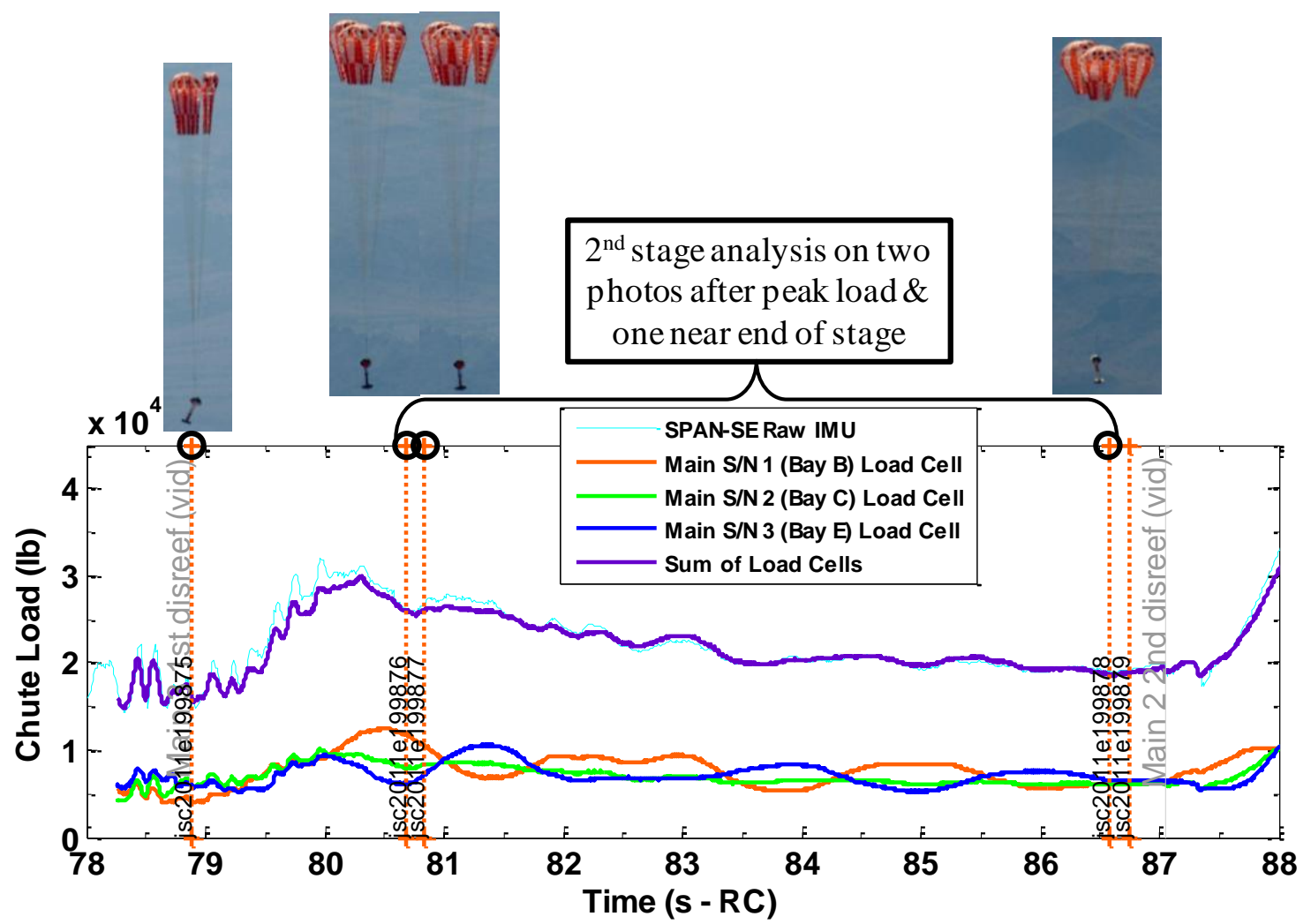

Figure 10. Photographs synchronized to Main $2^{\text {nd }}$ stage parachute loads during CDT-3-1. 
The over-inflation angles and suspension line half convergence angles for each parachute are plotted vs. time in Figure 11. The values listed for S/N 3 and S/N 2 represent averages from the left and right side of the respective canopy. Then the data from both canopies were averaged to generate the "circularized" angles. For each stage, the averaged suspension line half angles match favorably with the theoretical values assuming a circular reefing line.
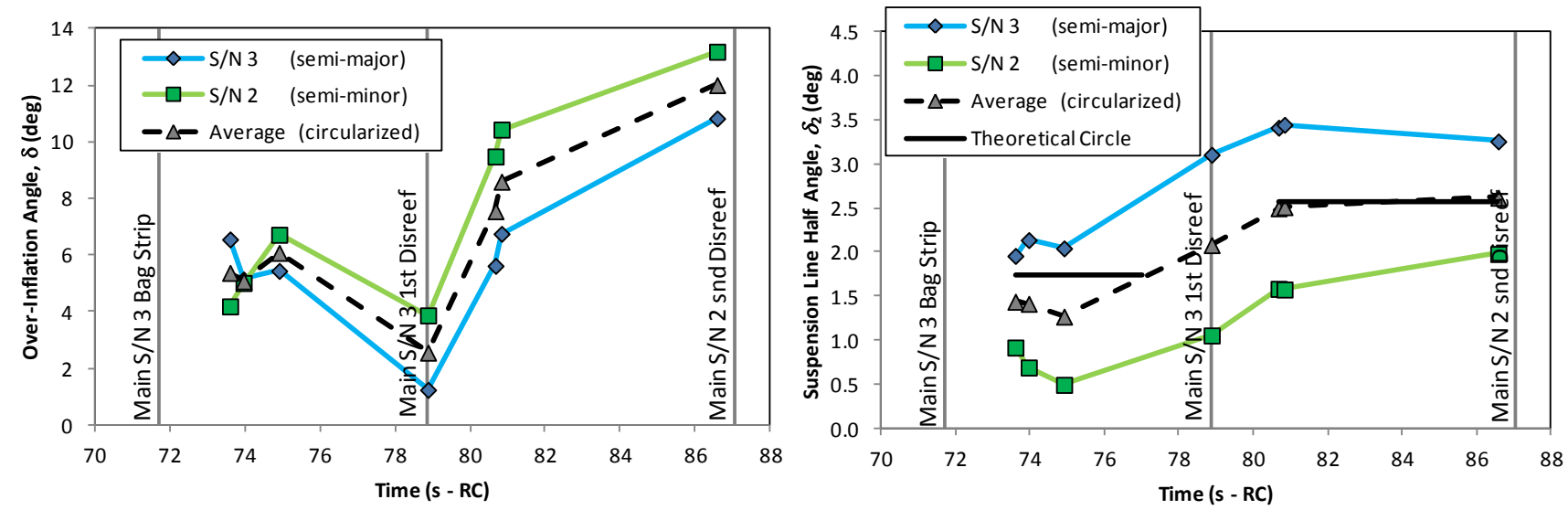

Figure 11. Measured Main parachute geometry vs. time for CDT-3-1.

Because multiple parachutes in the cluster were used to estimate the "circularized" Main parachute geometry, all three riser loads were averaged to be the effective reefed axial parachute force $\left(\mathrm{F}_{\mathrm{R}}\right)$, as plotted in Figure 12. These angles and axial load were then used to calculate the reefing line tension according to Eq. 3. The reefing tension is plotted on the secondary axis in the figure.

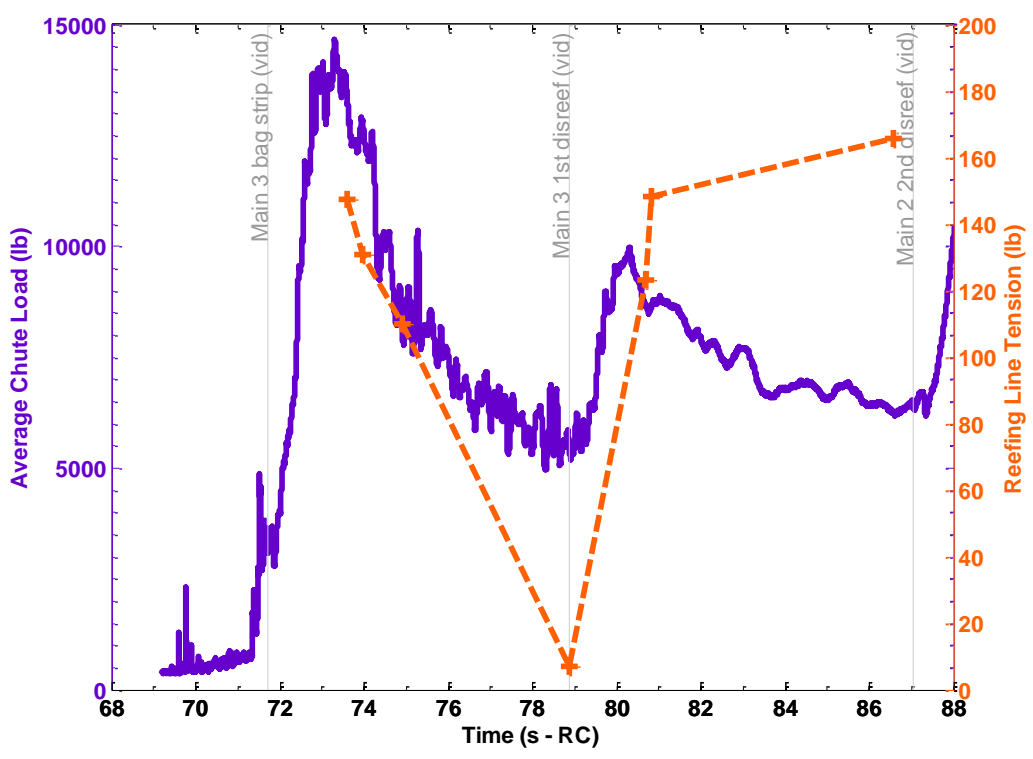

Figure 12. Synchronized parachute reefed axial load and corresponding reefing line tension for CDT-3-1.

\section{B. CDT-3-6: More Photographs}

As the previous tests indicate, in order to better understand the reefing line tension history, a sufficient number of photographs must be available throughout the reefed Main phase. The photographers had been making an effort to take as many pictures as possible, especially during dynamic events such as inflation. An investigation was made into the effectiveness of the burst mode of the camera hardware. Previously, images were saved in the lossless ".TIF" format. However, it was discovered that photos saved in the ".jpg" format were written to the memory card faster, resulting in a higher frame rate. This is a "lossy" format, so compression artifacts were possible. However, it was judged that this effect was less important than a high capture rate and could be mitigated by optimal positioning of the chase aircraft. 
It can be seen from Figure 13 and Figure 14 that this method was successful in capturing a large number of photographs during the Main parachute deployment and first stage inflation. Photogrammetric analysis was performed on 14 out of the 31 appropriate photos during the first stage, indicated by circles. There was a brief pause in the photograph collection during the first disreef, but photography resumed through the end of the second stage. Analysis was performed on 10 out of the 28 relevant photos for second stage.

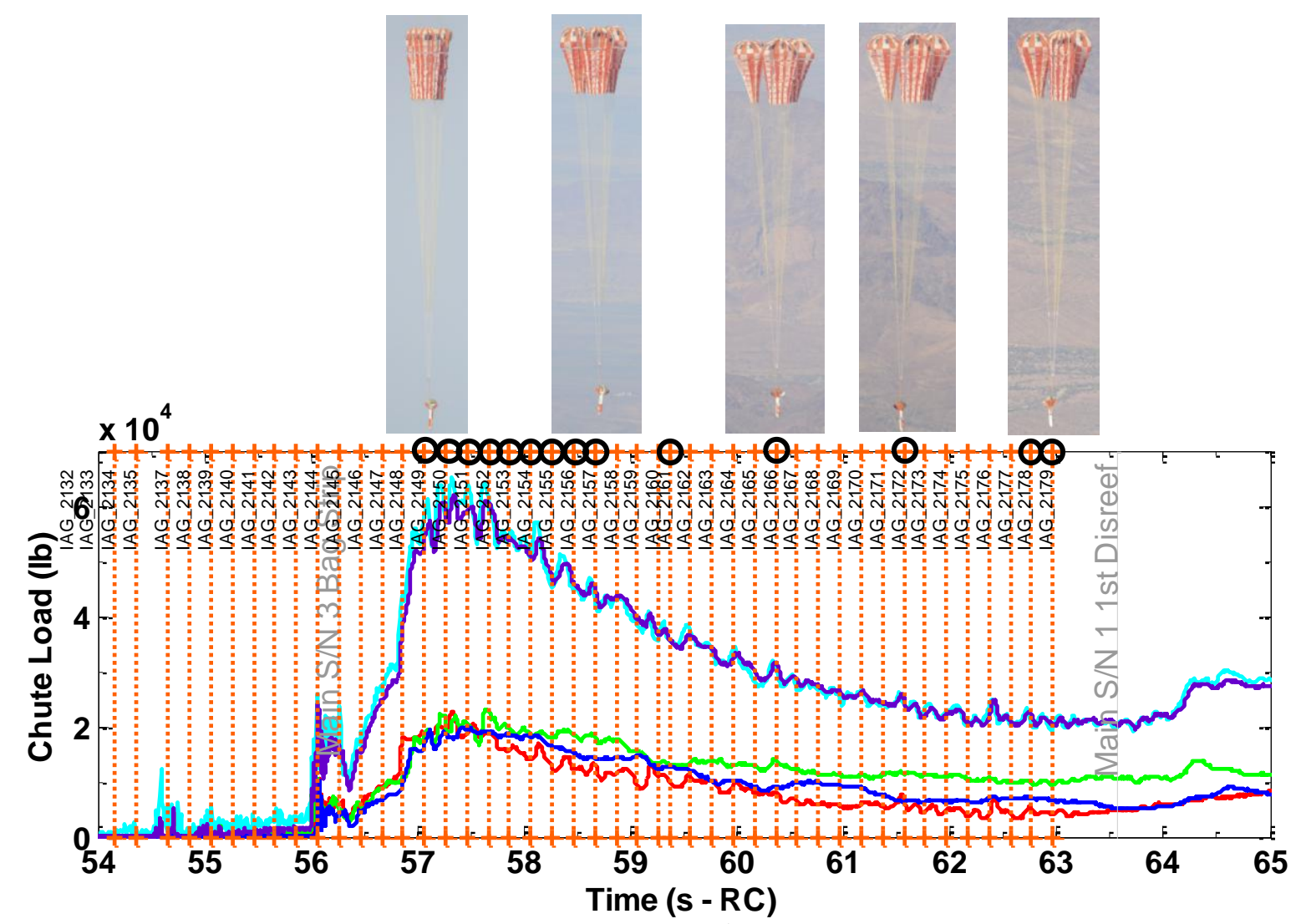

Figure 13. Photographs synchronized to Main $1^{\text {st }}$ stage parachute loads during CDT-3-6. 


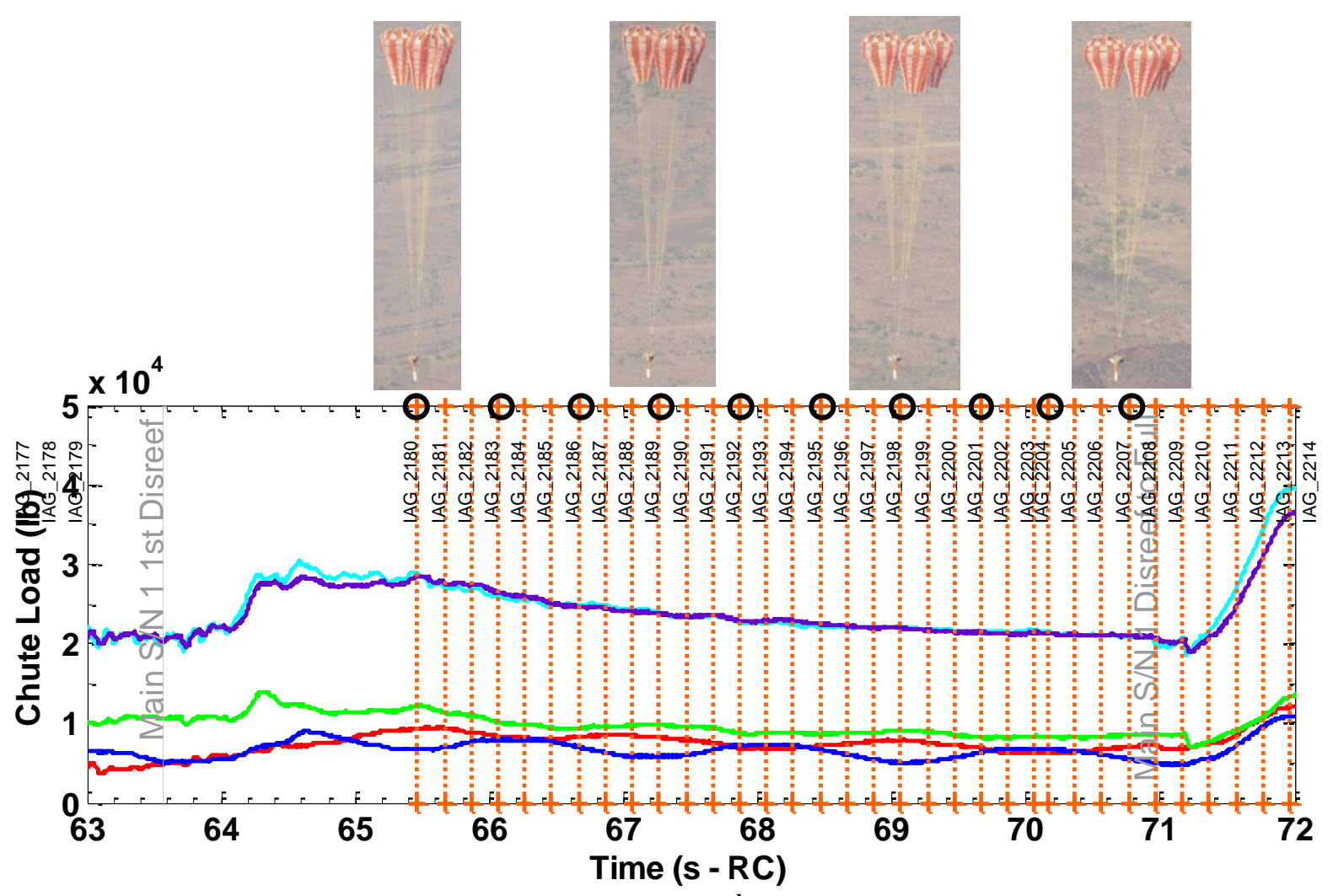

Figure 14. Photographs synchronized to Main $2^{\text {nd }}$ stage parachute loads during CDT-3-6.

As with CDT-3-1, geometric angles were measured for all three Main parachutes in the cluster. The chase helicopter images appeared to capture the semi-major axis of Main S/N 1. It was assumed that Main S/N 2 and $\mathrm{S} / \mathrm{N} 3$ were each relevant to the semiminor axis, though S/N 1 may have been foreshortened and the others might be forelengthened. A typical annotated image is shown in Figure 15.

The analysis was somewhat complicated relative to CDT-3-1 because only the outside edges of $\mathrm{S} / \mathrm{N} 2$ and $\mathrm{S} / \mathrm{N} 3$ were visible during most of the frames. The suspension line half convergence angle is measured relative to the centerline, which is usually determined from the triangle formed by points $\mathrm{A}, \mathrm{B}$, and $\mathrm{C}$. In this case, the apex of each hidden canopy was tracked to generate a centerline between each apex and its corresponding suspension line confluence (point A).

The method in measuring the overinflation angle has changed slightly from CDT-3-1. Previously, this angle was measured to be approximately tangent to the canopy near the skirt by choosing points D

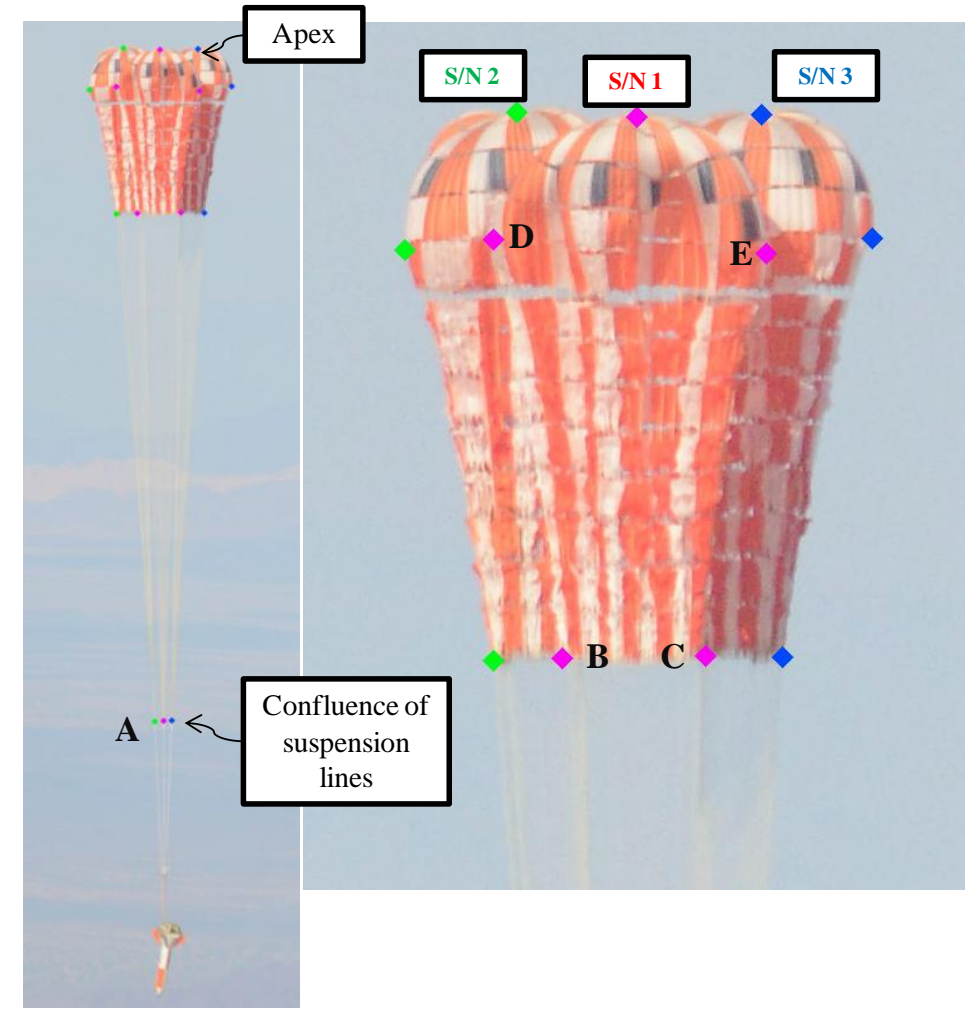

Figure 15. Main parachute geometry for CDT-3-6. 
and E level with the top edge of sail 8 (second from the bottom, as marked in Figure 6). However, in order to be conservative, it was decided to choose points $\mathrm{D}$ and $\mathrm{E}$ wherever the canopy billowed out furthest to create the largest over-inflation angle. Because maximizing the over-inflation angle ensures a conservative estimate of the reefing line tension, this method was also used for CDT-3-5 analysis.

The resulting geometric angles for CDT-3-6 are plotted in Figure 16. The difference in $\delta_{2}$ between the semimajor and semi-minor axes during the first stage indicates a large eccentricity in the skirt. However, these start to converge near the end of the second stage, indicating that the skirt is becoming more circular.
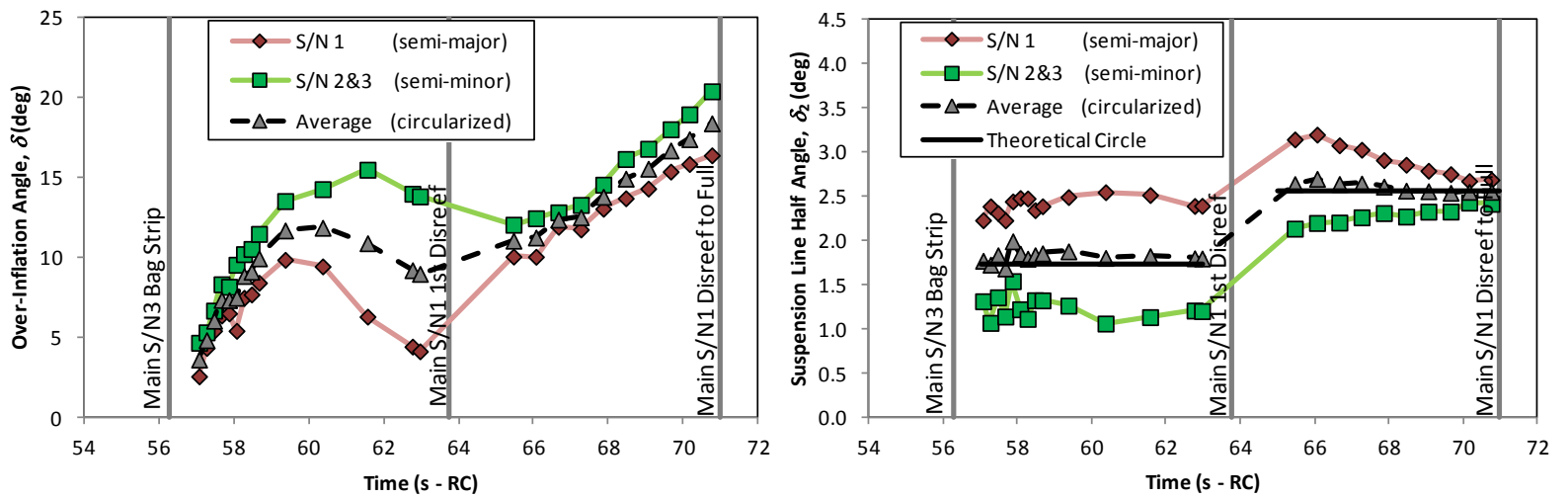

Figure 16. Measured Main parachute geometry vs. time for CDT-3-6.

In order to demonstrate the change of skirt shape, an ellipse was constructed at each instant using the suspension line half convergence angles and the known suspension line length to compute the size of a and b. These shapes are plotted in Figure 17 in the X-Y skirt plane (left) and as a function of time (right). Upward-looking cameras on the test vehicle may provide confirmation of this shape data, though the analysis to date has only been conducted on fully inflated canopies.

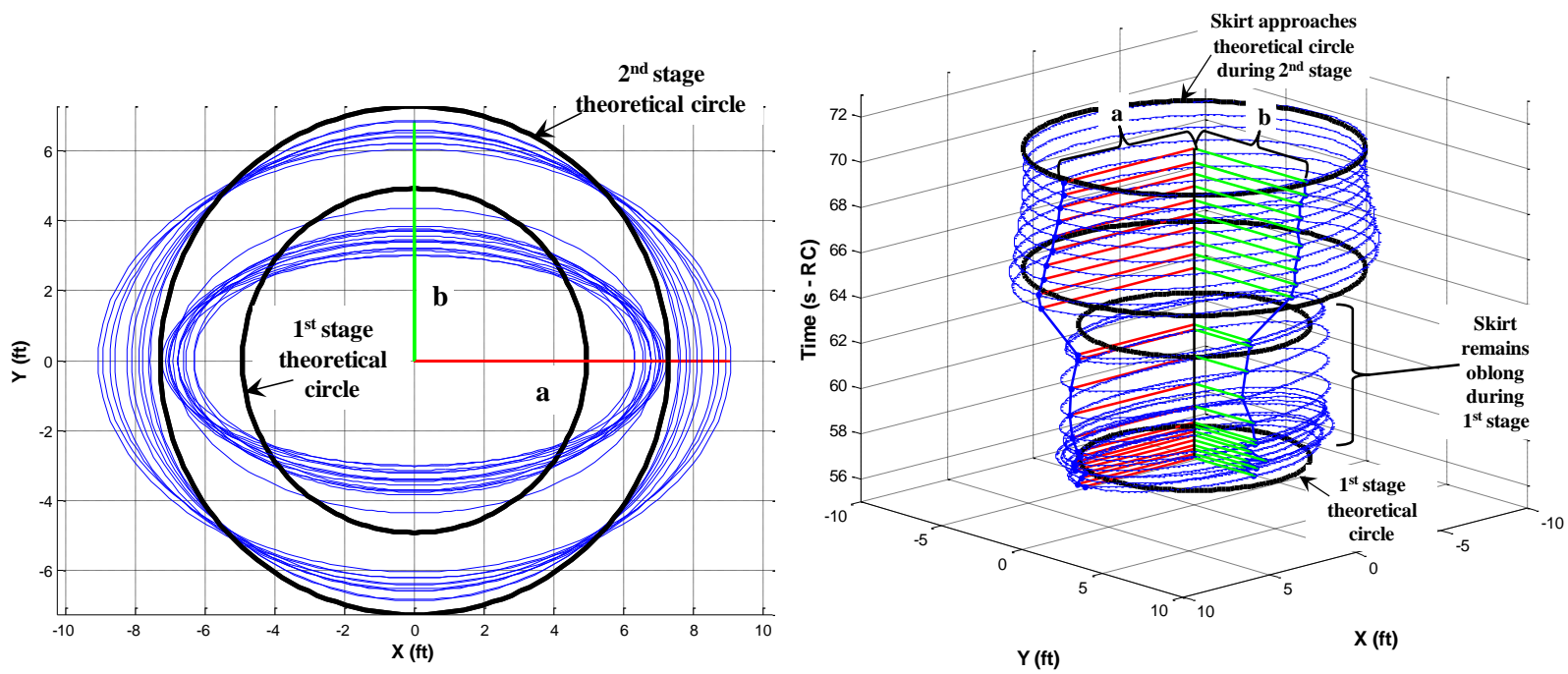

Figure 17. Effective cluster reefed elliptical skirt shapes for CDT-3-6. 
An average cluster load was used to estimate the reefing line tension based on the geometry at that instant. The average load and reefing line tension are plotted in Figure 18. Because more photos were available, the trends are much more apparent than they were for CDT-3-1. The peak axial load occurred $1.31 \mathrm{~s}$ earlier than the maximum reefing tension. This is within the experience of the Apollo series 80 and 81 flight tests, where the peak reefing line tension occurred between 0.45 and $2.8 \mathrm{~s}$ after the peak axial force. ${ }^{17}$

While both parameters tended to rise then fall during the first stage, the reefing line tension was still increasing at the end of the second stage, though the axial force had decayed to a steady-state value. This is consistent with the end of CDT-3-

1. However, there may be a perspective effect reducing measurement precision. The payload is descending faster than the chase helicopter, so the view is becoming less orthogonal to the parachute axis as time goes on.

\section{CDT-3-5: One EDU Main Skips First Stage}

CDT-3-5 was the second EDU test using the capsule-shaped Parachute Test Vehicle (PTV). One of the primary objectives of CDT-3-5 was to observe the effects of a skipped first stage on one of the Mains. This was accomplished by pre-cutting the first stage reefing line of Main S/N 7. As seen in the photograph in Figure 19, the skipping Main dominated the cluster. This is also apparent in the loads traces in Figure 20. Because the axial loads were relatively low in Mains $\mathrm{S} / \mathrm{N} 8$ and S/N 9, reefing analysis was only conducted on Main S/N 7. Only four photographs were taken of the inflated reefed Main parachutes and are therefore appropriate for analysis. These points are circled in Figure 20.

Because the non-skipping Mains offer much less aerodynamic interference than on a standard cluster test (where all Mains are in second stage), Main S/N 7 appears to be nearly axisymmetric, reminiscent of a single-Main flight during second stage. Since only one perspective of Main S/N 7 is available from the chase helicopter, it will have to be assumed to have a circular skirt.

The resulting geometric angles for Main S/N 7 are plotted in Figure 21. Main $\mathrm{S} / \mathrm{N} 7$ has a much more bulbous shape, resulting in a large over-inflation angle. In fact, the measured over-inflation angle is about twice as high as the second stage cluster during CDT-3-1. The suspension line half convergence angle is close to that of a theoretical circle with a circumference equal to the length of the second stage reefing line. This validates the circular skirt assumption for that canopy.

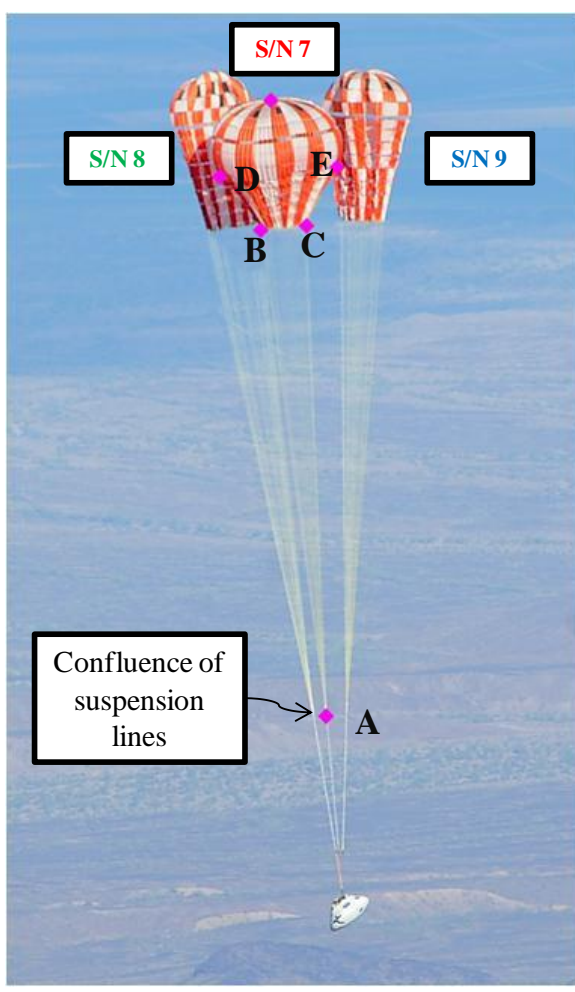

Figure 19. Parachute geometry for skipped $1^{\text {st }}$ stage during CDT-3-5. 


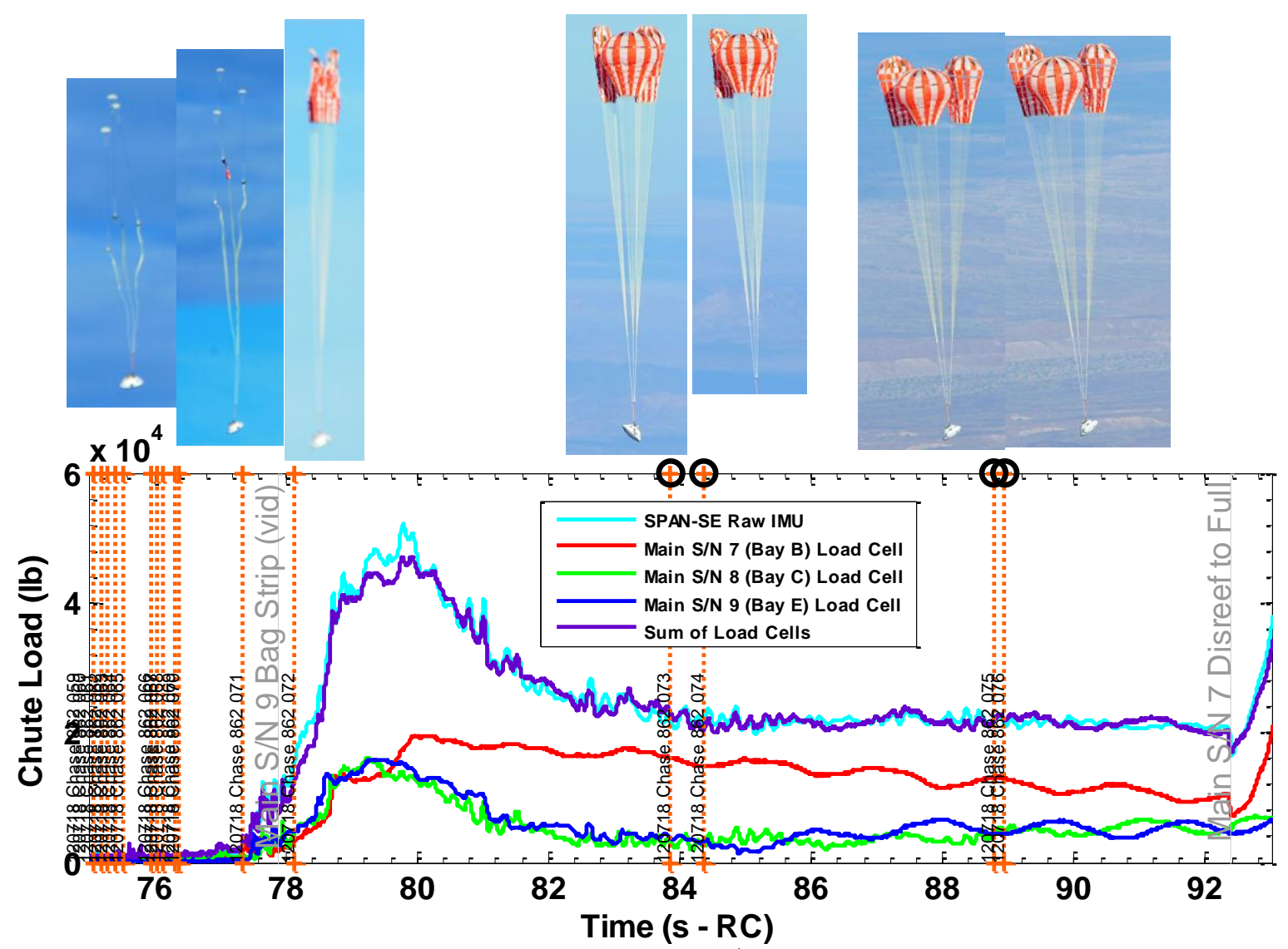

Figure 20. Photographs synchronized to Main skip $1^{\text {st }}$ stage parachute loads during CDT-3-5.
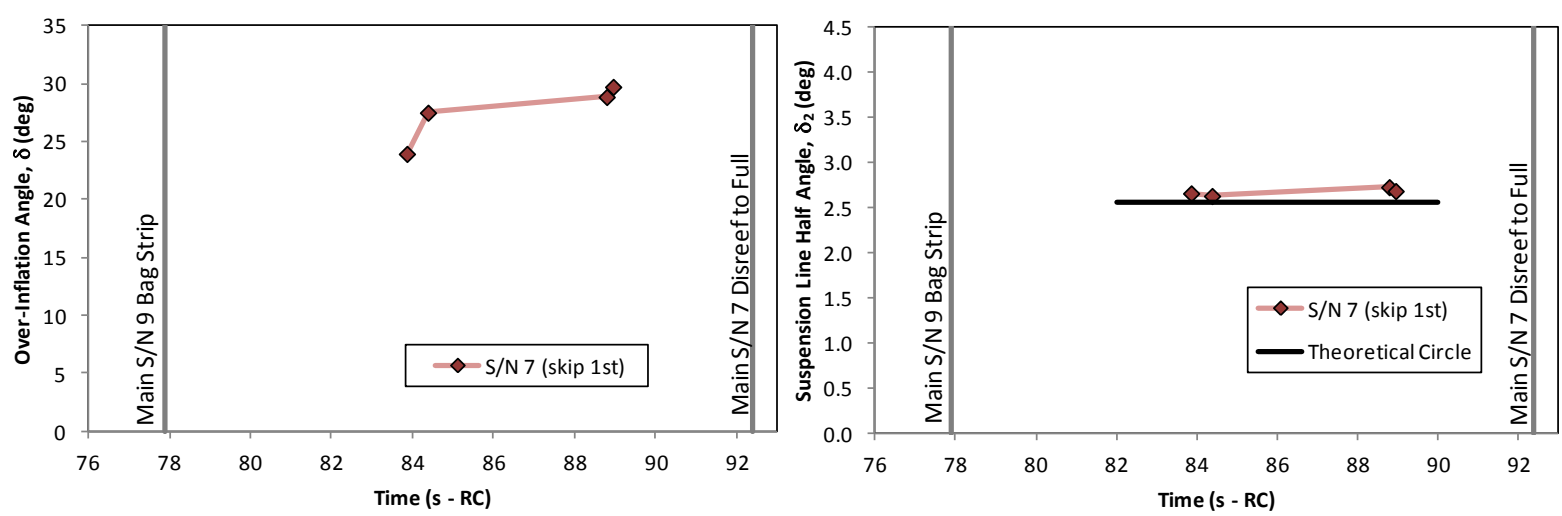

Figure 21. Measured Main parachute geometry vs. time for CDT-3-5. 
Because the reefing analysis was only performed on Main S/N 7, there was no need to average the cluster load as on CDT-3-1 and CDT-3-6. The reefing line tension on Main $\mathrm{S} / \mathrm{N} 7$, plotted in Figure 22, was based on the measured angles and axial force for that parachute.

The reefing line tension is significantly higher than that computed from the nominal tests for two reasons. The Main skipping first stage will take the majority of the cluster load. The reduced volume of the neighboring parachutes will tend to circularize the skirt and allow for a bulbous shape with a high over-inflation angle. This could be a concern because the skipped stage scenario already involves one failure to which the system is designed to be tolerant. However, a failure of the second stage reefing line due to the high tension would significantly increase the chances of a failed recovery.

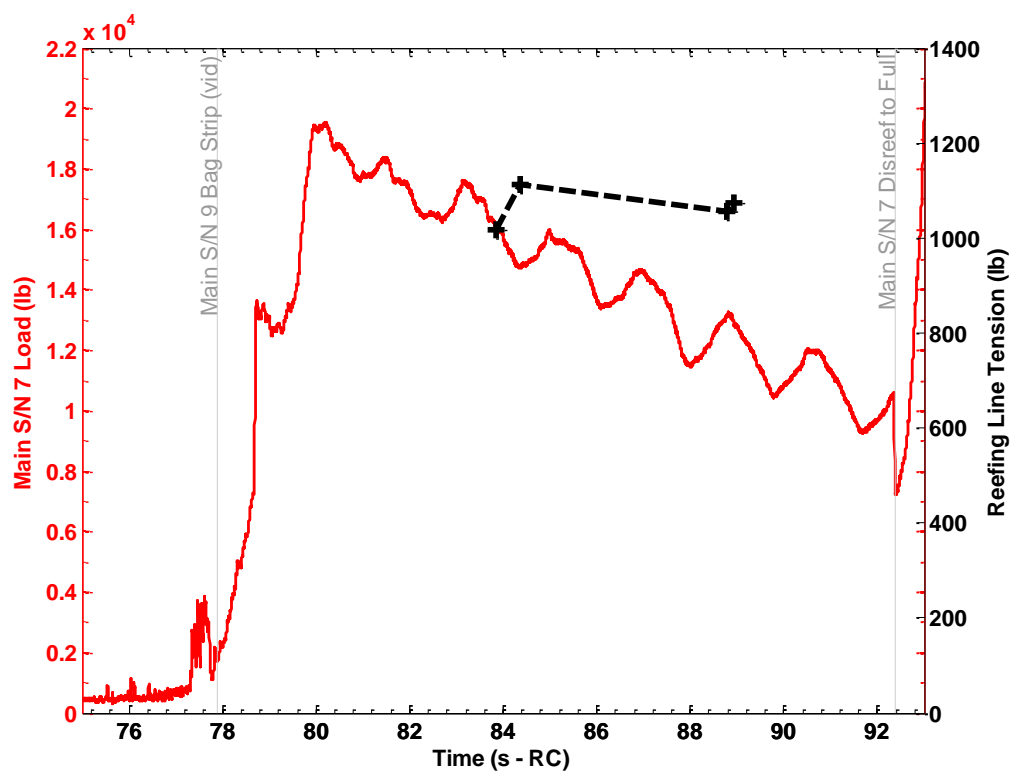

Figure 22. Synchronized parachute reefed axial load and corresponding reefing line tension for skipped stage of CDT-3-5.

\section{Conclusion}

Reefing line tension forces in EDU Main parachutes are determined by synchronizing riser tension data with over-inflation angles. Main parachute geometry is obtained through analysis of photographs captured by a chase helicopter which is staged to be approximately level with the Main parachutes during inflation. Despite two timestamps in the metadata of each file, synchronization must be accomplished manually to the precision required for analysis.

Because the Mains in a cluster have an elliptical shape, the over-inflation angle varies based on the perspective. A cluster of parachutes may offer extreme shapes, so the data can be averaged to an equivalent circular shape, assuming the canopies each evolve similarly and share the load about evenly. A single skipped stage will result in one canopy taking most of the load, and the shape will be drastically different than the others due to its dominance of the airflow. Test data showed that a skipped first stage resulted in a reefing line tension over three times more than a nominal cluster reefing sequence.

Further analysis of the inferred eccentricity caused by a cluster may provide insight into asymmetric loads experienced by the Ares and Orion programs.

\section{Acknowledgments}

The author wishes to thank the video and still photographers from NASA and YPG for their continued excellent coverage of flight tests and their cooperation in synchronizing photographs.

\section{References}

\footnotetext{
${ }^{1}$ Machín, R. A., Stewart, C. E., Evans, C. T., McMichael, J. H., "Human Rating the Orion Parachute System" $21^{s t}$ AIAA Aerodynamics Decelerator Systems Technology Conference, Dublin, Ireland, May 2011, AIAA paper 2011-2502.

${ }^{2}$ Varela, J. G. and Ray, E. S., "Skipped Stage Modeling and Testing of the Capsule Parachute Assembly System," $22^{\text {nd }}$ AIAA Aerodynamic Decelerator Systems Technology Conference, Daytona Beach, Florida, March 2013 (submitted for publication).

${ }^{3}$ Knacke, T. W., Parachute Recovery Systems Design Manual, NWC TP 6575, $1^{\text {st }}$ ed., Para Publishing, Santa Barbara, California, 1992.
} 
${ }^{4}$ Ray, E. S., Bretz, D. R., and Morris, A. L., "Photogrammetric Analysis of CPAS Main Parachutes," $21^{\text {st }}$ AIAA Aerodynamics Decelerator Systems Technology Conference, Dublin, Ireland, May 2011, AIAA paper 2011-2538.

${ }^{5}$ Potvin, J., Patel, S., "Simple Calculations of Skirt Reefing Line Tension on Low-Porosity Canopies Used at Very Small Reefing Ratios," $20^{\text {th }}$ AIAA Aerodynamics Decelerator Systems Technology Conference, Seattle, Washington, May 2009, AIAA paper 2009-3005.

${ }^{6}$ Wolf, D. and Fallon, E. J., "Reefing Line Loads for Ares Parachutes," $21^{\text {st }}$ AIAA Aerodynamics Decelerator Systems Technology Conference, Dublin, Ireland, May 2011, AIAA paper 2011-2619.

${ }^{7}$ Kidane, B. A., "Parachute Drag Area Using Added Mass as Related to Canopy Geometry," 20 ${ }^{\text {th }}$ AIAA Aerodynamics Decelerator Systems Technology Conference, Seattle, Washington, May 2009, AIAA paper 2009-2942.

${ }^{8}$ Schmidt, J. R., McFadden, P. G., and Pritchett, V. E., "Parachute Asymmetry in Ares Development Tests," $21^{\text {st }}$ AIAA Aerodynamics Decelerator Systems Technology Conference, Dublin, Ireland, May 2011, AIAA paper 2011-2575.

${ }^{9}$ Morris, A. L., Olson, L. M., Taylor, T., "Load Asymmetry Observed During Orion Main Parachute Inflation," $21^{\text {st }}$ AIAA Aerodynamics Decelerator Systems Technology Conference, Dublin, Ireland, May 2011, AIAA paper 2011-2611.

${ }^{10}$ Tezduyar, T. E., “Team for Advanced Flow Simulation and Modeling,” URL: http://www.tafsm.org/ [cited 10 Jan 2013 ].

${ }^{11}$ Christopher, J. D., "Computational Aerodynamic Modeling of the Reefed Stages of Ringsail Parachutes," M.S. thesis, Rice University, Houston, Texas, April 2009.

${ }^{12}$ Moorman, C. J., "Fluid-Structure Interaction Modeling of the Orion Spacecraft Parachutes," M.S. thesis, Rice University, Houston, Texas, April 2010.

${ }^{13}$ Ray, E. S. and Bretz, D. R., "Improved CPAS Photogrammetric Capabilities for Engineering Development Unit (EDU) Testing," $22^{\text {nd }}$ AIAA Aerodynamic Decelerator Systems Technology Conference, Daytona Beach, Florida, March 2013 (submitted for publication).

14“"GIMP - The GNU Image Manipulation Program,” URL: www.gimp.org [cited 12 August 2012].

${ }^{15}$ Ray, E. S., and Morris, A. L., "Measurement of CPAS Main Parachute Rate of Descent," $21^{\text {st }}$ AIAA Aerodynamic Decelerator Systems Technology Conference, Dublin, Ireland, May 2011, AIAA paper 2011-2545.

${ }^{16}$ Ray, E. S., "Reconstruction of Orion EDU Parachute Inflation Loads," $22^{\text {nd }}$ AIAA Aerodynamic Decelerator Systems Technology Conference, Daytona Beach, Florida, March 2013 (submitted for publication).

${ }^{17}$ Knacke, T. W. and Engel, H., "Reefing of Parachutes Forces in Reefing Lines," ASD-TR-81-5029, October 1981, Aeronautical Systems Division, Air Force Systems Command, Write-Patterson Air Force Base, Ohio. 